$a^{2}+3$

UCRI -50698

MSTRP

EVIDENGE LOR THE FORMATION AND MOIION OF MOLECULAR HYDROGEN IN IRRADIATED LTHIUM HYDRIDE

Hermann. I evder

July 2,11969

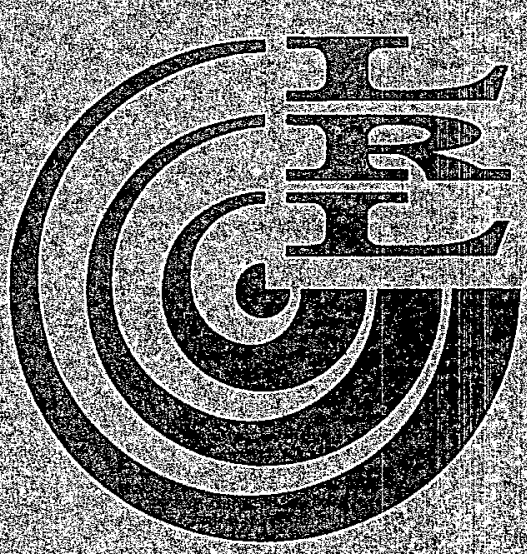

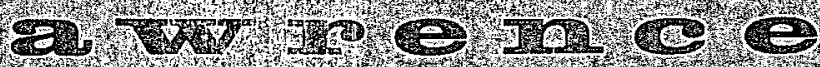

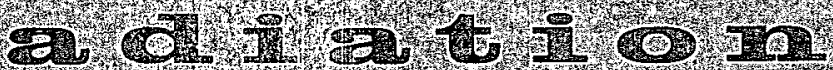

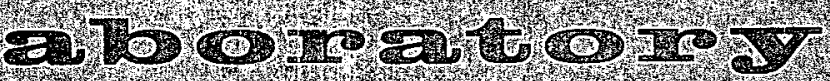

UNIVERSITYOF

BALIISWINA

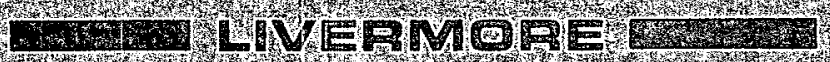




\section{DISCLAIMER}

This report was prepared as an account of work sponsored by an agency of the United States Government. Neither the United States Government nor any agency Thereof, nor any of their employees, makes any warranty, express or implied, or assumes any legal liability or responsibility for the accuracy, completeness, or usefulness of any information, apparatus, product, or process disclosed, or represents that its use would not infringe privately owned rights. Reference herein to any specific commercial product, process, or service by trade name, trademark, manufacturer, or otherwise does not necessarily constitute or imply its endorsement, recommendation, or favoring by the United States Government or any agency thereof. The views and opinions of authors expressed herein do not necessarily state or reflect those of the United States Government or any agency thereof. 


\section{DISCLAIMER}

Portions of this document may be illegible in electronic image products. Images are produced from the best available original document. 
Iavisomo IFadiatiom Iaboratory UNIVERSITY OF CALIFORNIA

LIVERMORE

\section{UCRL-50698 \\ EVIDENCE FOR THE FORMATION AND MOTION OF MOLECULAR HYDROGEN IN IRRADIATED LITHIUM HYDRIDE}

Herman R. Leider

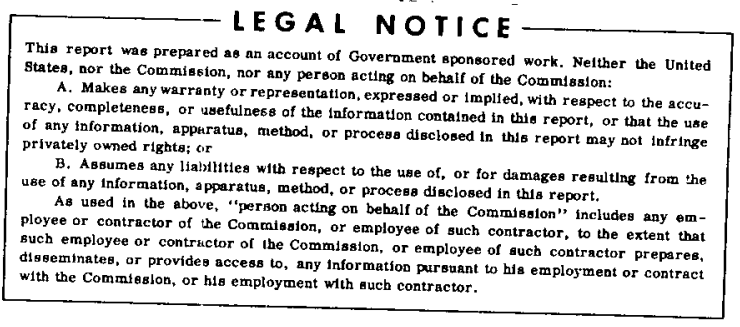

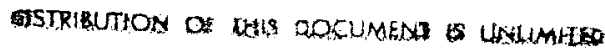




\title{
EVIDENCE FOR THE FORMATION AND MOTION OF MOLECULAR HYDROGEN IN IRRADIATED LITHIUM HYDRIDE
}

\begin{abstract}
It has been reported in a previous gives rise to the motionally narrowed study that the motionally narrowed hydrogen seen with pulsed nuclear magnetic resonance in irradiated $\mathrm{Li}\left({ }^{1} \mathrm{H},{ }^{3} \mathrm{H}\right)$ does not have the same isotopic composition as the original lithium hydride. This experiment has been repeated with a different isotopic composition to extend the range of the data. The hydrogen that NMR signal has been shown to be in high density gas bubbles that must form by diffusion processes. We propose that the difference in isotopic composition is due to the mass dependence in the diffusion coefficient, and arguments are given to support the idea that the diffusing species is molecular hydrogen.
\end{abstract}

\section{Discussion}

It is well established that irradiation of lithium hydride results in considerable decomposition of this material into lithium metal and hydrogen gas that remain trapped in the lattice. This is true whether the source of the radiation is external, such as $\gamma$-irradiation of $\mathrm{LiH},{ }^{1-4}$ or internal, such as in lithium hydride containing ${ }^{3} \mathrm{H}^{1,2}$

The hydrogen that is produced has properties expected of the gaseous molecular form ${ }^{2,3}$; in particular, an orthopara transition has been observed ${ }^{3}$ that is a positive indication of diatomic hydrogen. Furthermore, no paramagnetism has been detected in irradiated $\mathrm{LiH}$ by electron spin resonance that is not associated with either colloidal lithium metal or F-centers, even when irradiated at liquid nitrogen temperature. ${ }^{1}$ If irradiation were to produce atomic hydrogen, trapped somehow in the lattice, paramagnetism due to these atoms would be detectable. This, too, is evidence that the "free" hydrogen present is diatomic in nature. The $\mathrm{V}$-center absorption spectrum in irradiated $\mathrm{LiH}$ has also been attributed to molecular $\mathrm{H}_{2} \cdot{ }^{5}$ More direct evidence that hydrogen is present in gaseous form is the recent observation of cubic voids in irradiated LiH by electron microscope techniques. ${ }^{6}$ These voids are predominently oriented with their walls parallel to the [100] crystallographic directions. Upon observation of these voids, a nuclear magnetic resonance experiment (NMR) was performed on an irradiated single crystal to observe the angular variation of the spin-echo $\mathrm{T}_{2}$-relaxation time of the gaseous hydrogen as a function of crystal orientation relative to the applied magnetic field. ${ }^{7}$ The results are entirely 
consistent with the picture of hydrogen gas trapped in a cubic bubble. The variation of the NMR relaxation time with crystal orientation is as would be predicted from a model where loss of phase coherence of the $\mathrm{H}_{2}$ magnetic moments is due to interactions with the bubble walls.

Having firmly established that irradiation of lithium hydride produces diatomic hydrogen that is ultimately trapped in voids as a dense gas, it remains to be explained how microscopic pockets of gas actually form. A particularly important clue is found in the observation that for $\mathrm{Li}\left({ }^{1} \mathrm{H},{ }^{3} \mathrm{H}\right)$ the ratio of "free" tritium to hydrogen found by NMR is significantly different from the isotopic ratio of the material. ${ }^{2}$

Consider the following model. We assume that in $\mathrm{Li}\left({ }^{1} \mathrm{H},{ }^{3} \mathrm{H}\right)$ the steady-state concentration of gaseous species containing ${ }^{1} \mathrm{H}$ and/or ${ }^{3} \mathrm{H}$ is determined by the efficiency of the radiation process in ionizing the ${ }^{1} \mathrm{H}^{-}$and ${ }^{3} \mathrm{H}^{-}$ions and by the rate at which the species formed recombine with lithium. The gas that collects in bubbles is assumed to sample the steady-state distribution of molecules or atoms produced in the system by radiation. We assume that the efficiency of ionization for ${ }^{1} \mathrm{H}^{-}$and ${ }^{3} \mathrm{H}^{-}$is the same and, therefore, that the relative concentration of ${ }^{1} \mathrm{H}$ - and ${ }^{3} \mathrm{H}$-containing species as formed is statistically determined. Diatomic molecules exist in the gas bubbles, and we know that NMR sees only three-fourths of ${ }^{1} \mathrm{H}_{2}$ and ${ }^{3} \mathrm{H}_{2}$ because of the ortho-para equilibrium, but that all ${ }^{1} \mathrm{H}^{3} \mathrm{H}$ is seen. However, the weight given to the signal from ${ }^{1} \mathrm{H}^{3} \mathrm{H}$ is one-half that from ${ }^{1} \mathrm{H}_{2}$ or ${ }^{3} \mathrm{H}_{2}$ as its contribution to the spin count, since each molecule of ${ }^{1} \mathrm{H}^{3} \mathrm{H}$ has only one atom of each kind rather than two.

On the basis of the foregoing, three cases are easily visualized:

Case A: Radiation produces a monatomic specie $\left({ }^{1} \mathrm{H}\right.$ or $\left.{ }^{3} \mathrm{H}\right)$ that diffuses as a monatomic specie.

Production by radiation, $\mathrm{H}_{(\mathrm{c})}^{-} \rightarrow \mathrm{H}_{(\mathrm{c})}+\mathrm{e}$,

$$
\begin{aligned}
& \frac{\mathrm{d}\left[{ }^{1} \mathrm{H}\right]}{\mathrm{dt}}=\mathrm{k}\left[{ }^{\mathrm{H}^{-}}\right] \\
& \frac{\mathrm{d}\left[{ }^{3} \mathrm{H}\right]}{\mathrm{dt}}=\mathrm{k}\left[{ }^{3} \mathrm{H}^{-}\right]
\end{aligned}
$$

$$
\begin{aligned}
& \text { Recombination, } \mathrm{H}_{(\mathrm{c})}+\mathrm{Li}_{(\mathrm{c})} \rightarrow \mathrm{LiH}_{(\mathrm{c})}, \\
& -\frac{\mathrm{d}\left[{ }_{\mathrm{H}}\right\rfloor}{\mathrm{dt}}=\mathrm{KD}_{1_{\mathrm{H}}}\left[{ }^{1} \mathrm{H}\right] \\
& -\frac{\mathrm{d}\left[{ }^{3} \mathrm{H}\right]}{\mathrm{dt}}=\mathrm{KD}_{3_{\mathrm{H}}}\left[{ }^{3} \mathrm{H}\right]=\mathrm{K} \frac{\sqrt{3}}{3} \mathrm{D}_{{ }_{1} \mathrm{H}}\left[{ }^{3} \mathrm{H}\right]
\end{aligned}
$$

The terms in square brackets, [ ], always represent concentrations or fractional concentrations. $D_{i}$ is the appropriate diffusion coefficient of the ith specie. We assume that diffusion coefficients of similar ${ }^{1} \mathrm{H}$ and ${ }^{3} \mathrm{H}$ species differ only by a mass term.

At steady state:

$$
\begin{aligned}
& \mathrm{k}\left[{ }^{1} \mathrm{H}\right]=\mathrm{KD}_{1_{\mathrm{H}}}\left[{ }_{\mathrm{H}}\right] \\
& \mathrm{k}\left[{ }^{3} \mathrm{H}\right\rfloor=\mathrm{K} \frac{\sqrt{3}}{3} \mathrm{D}_{1_{\mathrm{H}}}\left\lceil{ }^{3} \mathrm{H}\right]
\end{aligned}
$$

so that

$$
\frac{\left|{ }^{3} \mathrm{H}\right|}{\left|{ }^{1} \mathrm{H}\right|}=\sqrt{3} \frac{\left.\mid{ }^{3} \mathrm{H}^{-}\right\rceil}{\left.\mid{ }^{1} \mathrm{H}^{-}\right\rceil}=\sqrt{3} \mathrm{R}_{\mathrm{I}}
$$

Here we assume that, since the gas appears as diatomic molecules, the formation of molecules occurs after the atoms 
reach the bubbles. Since the number of ${ }^{1} \mathrm{H}_{2}, \quad{ }^{3} \mathrm{H}_{2}$ and ${ }^{1} \mathrm{H}^{3} \mathrm{H}$ molecules depends on the quantity of each type of atom,

$$
\begin{aligned}
& {\left[{ }^{1} \mathrm{H}_{2}\right] \propto\left[{ }^{1} \mathrm{H}\right]^{2}} \\
& {\left[{ }^{3} \mathrm{H}_{2}\right] \propto\left[{ }^{3} \mathrm{H}\right]^{2}}
\end{aligned}
$$

and

$$
\left.\left({ }^{1} \mathrm{H}^{3} \mathrm{H}\right) \propto 2\left[{ }^{1} \mathrm{H}\right] \mid{ }^{3} \mathrm{H}\right)
$$

since $2 \mathrm{H} \rightleftharpoons \mathrm{H}_{2}$. Now the ratio of ${ }^{3} \mathrm{H}$ atoms to ${ }^{1} \mathrm{H}$ atoms is

$$
\mathbf{R}^{\prime}=\frac{\left.\left[{ }^{3} \mathrm{H}_{2}\right\rfloor+\frac{1}{2} \mid{ }^{1} \mathrm{H}^{3} \mathrm{H}\right)}{\left.\left[{ }^{1} \mathrm{H}_{2}\right]+\frac{1}{2} \mid{ }^{1} \mathrm{H}^{3} \mathrm{H}\right)}
$$

and the observed spin ratio is

$$
\mathrm{R}=\frac{\frac{3}{4}\left[{ }^{3} \mathrm{H}_{2}\right)+\frac{1}{2}\left[{ }^{1} \mathrm{H}^{3} \mathrm{H}\right]}{\left.\frac{3}{4}\left[{ }^{1} \mathrm{H}_{2}\right)+\frac{1}{2} \mid{ }^{1} \mathrm{H}^{3} \mathrm{H}\right]}
$$

Using relations (4) and (5)

$$
R_{A}=R_{I}\left(\frac{\frac{9}{4} R_{I}+\sqrt{3}}{\sqrt{3} R_{I}+\frac{3}{4}}\right)
$$

$R_{A}$ is plotted as a function of composition in Fig. 1 as curve A.

Case B: Radiation produces a diatomic specie $\left({ }^{1} \mathrm{H}_{2},{ }^{1} \mathrm{H}^{3} \mathrm{H}\right.$, or $\left.{ }^{3} \mathrm{H}_{2}\right)$, which then diffuses as a diatomic specie.

Production by radiation, $2 \mathrm{H}_{(\mathrm{c})}^{-} \rightarrow \mathrm{H}_{2(\mathrm{c})}$ $+2 \mathrm{e}$,

$$
\begin{aligned}
& \frac{\mathrm{d}\left[{ }^{1} \mathrm{H}_{2}\right]}{\mathrm{dt}}=\mathrm{k}\left[{ }^{1} \mathrm{H}^{-}\right]^{2} \\
& \frac{\mathrm{d}\left[{ }^{3} \mathrm{H}_{2}\right]}{\mathrm{dt}}=\mathrm{k}\left[{ }^{3} \mathrm{H}^{-}\right]^{2} \\
& \left.\frac{\mathrm{d}\left[{ }^{1} \mathrm{H}^{3} \mathrm{H}\right]}{\mathrm{dt}}=2 \mathrm{k}\left[{ }^{1} \mathrm{H}^{-}\right] \mid{ }^{3} \mathrm{H}^{-}\right]
\end{aligned}
$$

Recombination, $\left.\frac{1}{2} \mathrm{H}_{2(\mathrm{c})}+\mathrm{Li}_{(\mathrm{c})} \rightarrow \mathrm{LiH}_{(\mathrm{c})}\right)^{\prime}$

$$
-\frac{\mathrm{d}\left[{ }^{1} \mathrm{H}_{2}\right]}{\mathrm{dt}}=\mathrm{KD}_{1_{\mathrm{H}_{2}}}\left[{ }^{1} \mathrm{H}_{2}\right]
$$

$$
-\frac{\mathrm{d}\left\lceil{ }^{3} \mathrm{H}_{2}\right\rfloor}{\mathrm{dt}}=\mathrm{K} \frac{\sqrt{3}}{3} \mathrm{D}_{1_{\mathrm{H}_{2}}}\left[{ }^{3} \mathrm{H}_{2}\right\rfloor
$$

$$
\left.-\frac{\mathrm{d}\left\lfloor{ }_{\mathrm{H}}^{3} \mathrm{H}\right\rfloor}{\mathrm{dt}}=\mathrm{K} \frac{\sqrt{2}}{2} \mathrm{D}_{1_{\mathrm{H}_{2}}} \mid{ }^{1} \mathrm{H}^{3} \mathrm{H}\right\rfloor
$$

At steady state:

$$
\begin{aligned}
& \left.\mathrm{k}\left|1_{\mathrm{H}^{-}}\right|^{2}=\mathrm{KD}_{1_{\mathrm{H}_{2}}} \mid{ }^{1} \mathrm{H}_{2}\right\rfloor \\
& \mathrm{k}\left|{ }^{3} \mathrm{H}^{-}\right|^{2}=\mathrm{K} \frac{\sqrt{3}}{3} \mathrm{D}_{1_{\mathrm{H}_{2}}}\left|{ }^{3} \mathrm{H}_{2}\right| \\
& \left.2 \mathrm{k}\left[{ }^{1} \mathrm{H}^{-}\right] \mid{ }^{3} \mathrm{H}^{-}\right]=\mathrm{K} \frac{\sqrt{2}}{2} \mathrm{D}_{1_{\mathrm{H}_{2}}}\left[{ }^{1} \mathrm{H}^{3} \mathrm{H}\right]
\end{aligned}
$$

As in case $A$, the observed ratio,

$$
\mathrm{R}=\frac{\frac{3}{4}\left[{ }^{3} \mathrm{H}_{2}\right]+\frac{1}{2}\left[{ }^{1} \mathrm{H}^{3} \mathrm{H}\right]}{\frac{3}{4}\left[{ }^{1} \mathrm{H}_{2}\right]+\frac{1}{2}\left[{ }^{1} \mathrm{H}^{3} \mathrm{H}\right]}
$$

Using $9(\mathrm{a}, \mathrm{b}$ and $\mathrm{c})$,

$$
R_{B}=R_{I}\left(\frac{\frac{3}{4} \sqrt{3} R_{I}+\sqrt{2}}{\sqrt{2} R_{I}+\frac{3}{4}}\right)
$$

This is plotted as curve B in Fig. 1.

Case C: Radiation produces a diatomic species $\left({ }^{1} \mathrm{H}_{2},{ }^{3} \mathrm{H}_{2}\right.$, and $\left.{ }^{1} \mathrm{H}^{3} \mathrm{H}\right)$ that must dissociate into atoms in order to diffuse $\left({ }^{1} \mathrm{H}\right.$ and $\left.{ }^{3} \mathrm{H}\right)$.

Production by radiation, $2 \mathrm{H}_{(\mathrm{c})}^{-} \rightarrow \mathrm{H}_{2(\mathrm{c})}$ $+2 \mathrm{e}$,

$$
\frac{\mathrm{d}\left[{ }^{1} \mathrm{H}_{2}\right]}{\mathrm{dt}}=\mathrm{k}\left[{ }^{1} \mathrm{H}^{-}\right]^{2}
$$




$$
\begin{aligned}
& \frac{\mathrm{d}\left[{ }^{3} \mathrm{H}_{2}\right]}{\mathrm{dt}}=\mathrm{k}\left[\left.{ }^{3} \mathrm{H}^{-}\right|^{2}\right. \\
& -\frac{\mathrm{d}\left[{ }^{3} \mathrm{H}_{2}\right]}{\mathrm{dt}}=\mathrm{KD}_{3_{\mathrm{H}}}\left[{ }^{3} \mathrm{H}\right]=2 \mathrm{~K} \frac{\sqrt{3}}{3} \mathrm{D}_{1_{\mathrm{H}}}\left[{ }^{3} \mathrm{H}_{2}\right\rfloor \\
& \left.\frac{\mathrm{d}\left[{ }^{1} \mathrm{H}^{3} \mathrm{H}\right]}{\mathrm{dt}}=2 \mathrm{k}\left[{ }^{1} \mathrm{H}^{-}\right] \mid{ }^{3} \mathrm{H}^{-}\right]
\end{aligned}
$$

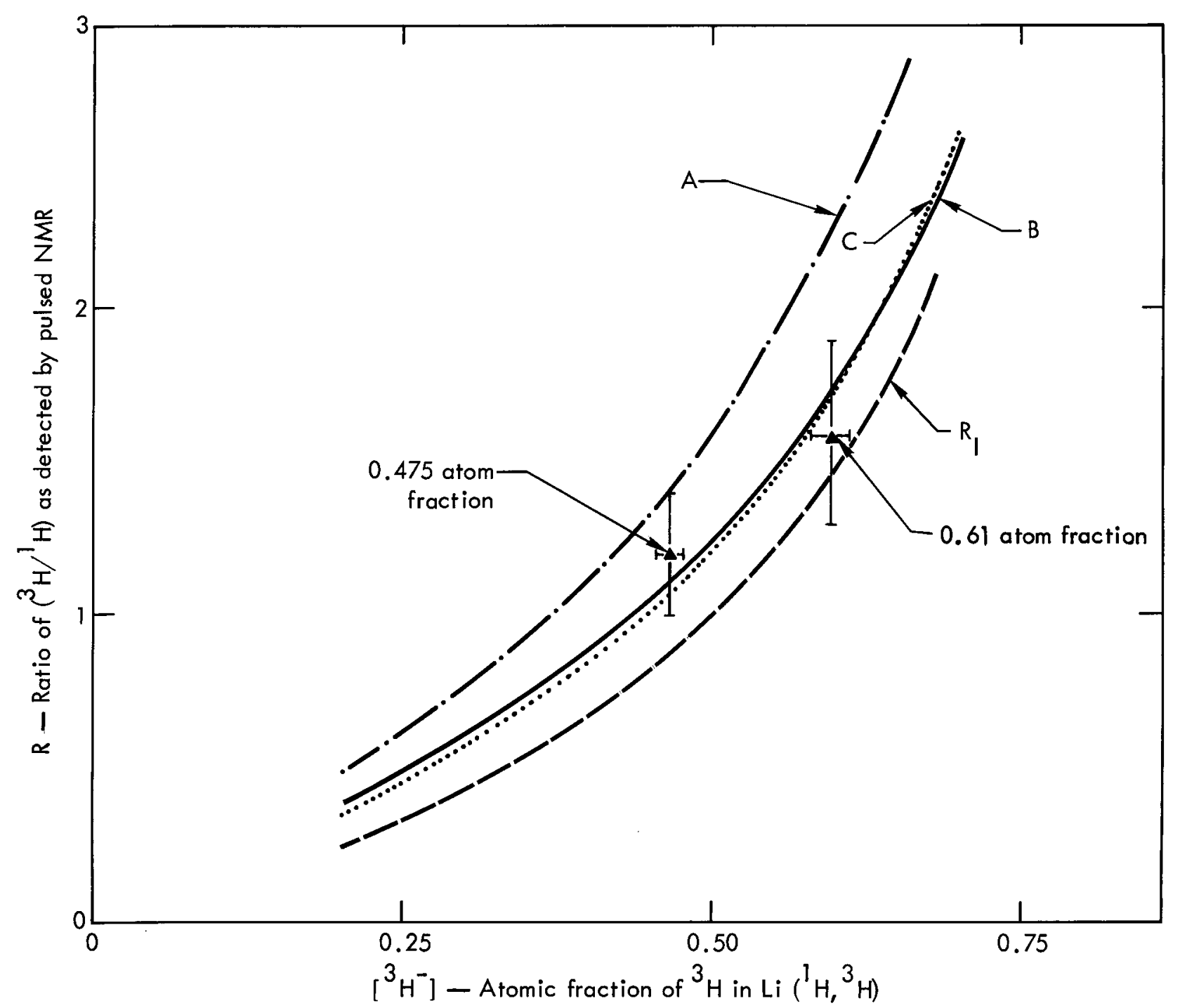

Fig. 1. The ratio of ${ }^{3} \mathrm{H}$ spins to proton spins plotted as a function of composition for three cases. 
Proceeding as before, we get

$$
R_{c}=R_{I}\left(\frac{\frac{3 \sqrt{3}+3}{8} R_{I}+1}{R_{I}+\frac{3 \sqrt{3}}{8}}\right) \text {, }
$$

which is plotted as curve $C$. On examination of Table I and Fig. 1, it is evident that cases $B$ and $C$ are not distinguished by the experimental results, and thus, either case may be valid. However, there are several plausibility arguments against case $\mathrm{C}$. The energy of dissociation of hydrogen molecules is so large that it would seem unlikely that dissociation would be a common event. Moreover, if such a dissociation did occur appreciably, one would expect to have seen some evidence for the presence of atomic hydrogen by such a sensitive probe as electron spin resonance, even if its average existence were short-lived.

Table I shows the results of NMR determination of the ${ }^{3} \mathrm{H} /{ }^{1} \mathrm{H}$ ratio ${ }^{2}$ for two compositions of $\mathrm{Li}\left({ }^{1} \mathrm{H},{ }^{3} \mathrm{H}\right)$ along with the calculated values of this ratio for cases $A$, $B$, and $C$; the values of the isotopic ratios for these two compositions are also shown. Figure 1 contains the plots for the two points representing the two compositions, the curve for the isotopic ratio, and the values calculated for the three cases discussed above. For the composition at 0.475 atom fraction of ${ }^{3} \mathrm{H}^{-}$, the point represents measurements on several samples stored at temperatures of from $\sim 25^{\circ} \mathrm{C}$ to $\sim 250^{\circ} \mathrm{C}$. The point at 0.61 atom fraction of ${ }^{3} \mathrm{H}^{-}$is from a single sample that was stored at $75^{\circ} \mathrm{C}$. The width in composition for each point represents the range of composition the sample has seen due to the radioactive decay of ${ }^{3} \mathrm{H}$. Although the experimental uncertainty in these measurements is quite large, it seems that case $\mathrm{A}$ is not a good description of results. Consequently, we may say that in the radiation decomposition of lithium hydride, the formation of bubbles of hydrogen gas proceeds by the production of hydrogen molecules and their subsequent aggregation into bubbles, probably by diffusion of molecules through the lattice to nucleation sites.

Table I. Isotopic ratios and observed and calculated ${ }^{3} \mathrm{H} /{ }^{1} \mathrm{H}$ ratios for two compositions of $\mathrm{Li}\left({ }^{1} \mathrm{H},{ }^{3} \mathrm{H}\right)$.

\begin{tabular}{llcccc}
\hline$\left[{ }^{3} \mathrm{H}^{-}\right]$ & $\begin{array}{l}\text { Isotopic } \\
\text { ratio, } \mathrm{R}_{\mathrm{I}}\end{array}$ & $\mathrm{R}_{\mathrm{A}}$ & $\mathrm{R}_{\mathrm{B}}$ & $\mathrm{R}_{\mathrm{C}}$ & $\mathrm{R}_{\text {(obs.) }}$ \\
\hline 0.475 & $0.905-0.83$ & 1.47 & 1.16 & 1.12 & $1.2 \pm 0.2$ \\
0.610 & $1.564-1.38$ & 2.38 & 1.82 & 1.84 & $1.6 \pm 0.3$ \\
\hline
\end{tabular}




\section{References}

1. F. E. Pretzel et al., "Properties of Lithium Hydride: V. Vacancy Formation, Cavitation and Lithium Precipitation in Irradiated Lithium Hydride," J. Appl Phys. 33 (Suppl.), 510 (1962); the unabridged version is Radiation Effects on Lithium Hydride, Los Alamos Scientific Laboratory, N. M., Rept. LA-2463 (1961).

2. P. C. Souers, T. A. Jolly, and C. F. Cline, "Pulsed Nuclear Magnetic Resonance Study of Irradiated Lithium Hydride," J. Phys. Chem. Solids 28, 1717 (1967).

3. P. C. Souers et al., Pulsed Nuclear Magnetic Resonance of Gamma-Irradiated Lithium Hydride, Lawrence Radiation Laboratory, Livermore, Rept. UCRL-71517 (1969); P. C. Souers et al., NMR and Electron Microscopy Studies on Irradiated Lithium Hydride, Lawrence Radiation Laboratory, Livermore, Rept. UCRL-71835 (1969).

4. H. W. Newkirk and H. R. Leider, Thermal Annealing of Irradiated Lithium Hydride:

I. Measurement of Stored Energy, Lawrence Radiation Laboratory, Livermore, Rept. UCRL-71850 (1969); H. R. Leider, Thermal Annealing of Irradiated Lithium Hydride: II. A Proposed Mechanism, Lawrence Radiation Laboratory, Livermore, Rept. UCRL-71851 (1969).

5. F. E. Pretzel and C. C. Rushing, "Properties of Lithium Hydride: II. Optical Absorption by Color Centers," J. Phys. Chem. Solids 17, 232 (1961).

6. T. Imai, Observation of Bubbles in Gamma-Irradiated Lithium Hydride, Lawrence Radiation Laboratory, Livermore, Rept. UCRL-71730 (1969); and Phil. Mag. (to be published).

7. P. C. Souers, T. S. Blake, and R. M. Penpraze, NMR Anisotropy in Irradiated Lithium Hydride, Lawrence Radiation Laboratory, Livermore, Rept. UCRL-71698 (1969); and Phil. Mag. (to be published). 


\section{Distribution}

\section{$\underline{\text { LRL Internal Distribution }}$}

Michael M. May

G. Dorough

H. Weed

A. Karo

B. Rubin

G. D. Snider

H. Otsuki

J. S. Kane

A. J. Rothman

D. Coronado

C. Cline

H. Leider

T. Imai

P. C. Souers

T. Blake

H. Newkirk

J. Mitchell

R. Penpraze

G. Smith

C. Griffith

J. B. Holt

R. H. Conit

TID Berkeley

TID File

External Distribution

C. H. Ice

J. H. Owen

Savannah River Laboratory

Aiken, South Carolina

D. T. Vier

J. Anderson

Los Alamos Scientific Laboratory

Los Alamos, New Mexico

F. Fushimi

Mound Laboratory

Miamisburg, Ohio 


\section{External Distribution (Continued)}

W. Wilson

Sandia Laboratories

Livermore, California

P. W. Levy

Brookhaven National Laboratory

Upton, New York

TID-4500 Distribution, UC-4, Chemistry

LEGAL NOTICE

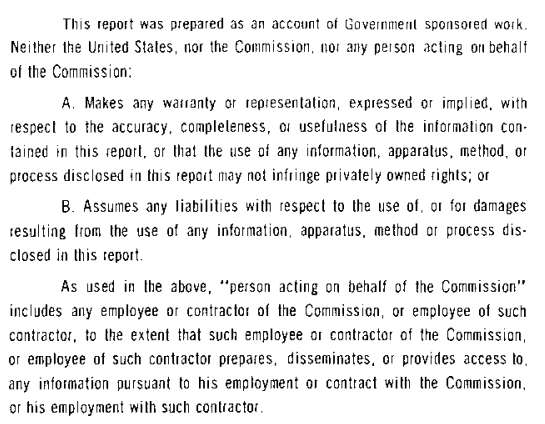

Printed in USA. Available from the Clearinghouse for Federal Scientific and Technical Information, National Bureau of Standards, U.S. Department of Commerce, Springfield, Virginia 22151

Price: Printed Copy \$3.00; Microfiche $\$ 0.65$. 